\title{
Distribuição, Mobilidade e Polarização de Renda no Brasil: 1987 A 2003
}

\author{
Erik Alencar de Figueirêdo*, José Luis da Silva Netto Junior ${ }^{\dagger}$, Sabino \\ da Silva Porto Junior ${ }^{\ddagger}$
}

Sumário: 1. Introdução; 2. Capital Humano e Mobilidade de Renda; 3. Métodos de Inferência; sultados; 5. Considerações Finais; A. Índice de Gini, Polarização e Mobilidade Educacional. Palavras-chave: Mudança Tecnológica; Desigualdade; Mobilidade; Polarização de Renda. Códigos JEL: 015; R11; I21.

Este estudo busca investigar o padrão de transformação da distribuição pessoal de renda brasileira e de suas regiões geográficas no período de 1987 a 2003. Procura-se ainda identificar os fatores motivadores de tal transformação ressaltando os aspectos inerentes às mobilidades de renda e educacional. Para tanto, utilizam-se uma série ferramentais estáticos e dinâmicos, onde se destacam a medida de polarização de renda proposta por Duclos et alii (2004) e o cálculo das matrizes de transição de probabilidade. Os resultados apontam uma substancial mudança na distribuição de renda brasileira. Grosso modo, observou-se a polarização dos salários nas faixas de renda inferiores e superiores. Este movimento foi acompanhado por um intenso aumento na mobilidade educacional, que por sua vez, está associado a um decréscimo do efeito familiar. No entanto, tal comportamento se dá de forma diferenciada no âmbito regional.

This study aims to investigate the pattern of transformation of the Brazilian income distribution its geographic regions in the period 1987 - 2003. It also intends to identify the underlying factors of such transformation, specifically, the income and educational mobilities. To achieve that, static and dynamic tools have been used. Among those tools, the polarization measures proposed by Duclos et alii (2004) and the matrix transition of probability can be highlighted. The results show a great change in the Brazilian income distribution. In general, it was observed a polarization of the wages featured by an increase in both

\footnotetext{
* Aluno do Curso de Doutorado em Economia - UFRGS. E-mail: erik \protect \_cme@yahoo.com.br.

${ }^{\dagger}$ Aluno do Curso de Doutorado em Economia - UFRGS. E-mail: juniorluis@yahoo. com.

${ }^{\ddagger}$ Professor do Programa de Pós-Graduação em Economia - UFRGS. E-mail: sabino@ppge1 .ppge.ufrgs . br.
} 
the bottom and the top salary levels. These changes were followed by a strong educational mobility related to a decrease in the parental effect. However, differences among the regions connected to that process could also be found.

\section{INTRODUÇÃO}

No final da década de 1980, a economia brasileira passou por um forte processo de liberalização comercial. Foram eliminadas as barreiras tarifárias e não-tarifárias resultando, entre outros fatos, em um aumento da participação das exportações no produto interno bruto. Concomitante a este processo de mudança nas relações econômicas entre o Brasil e o resto do mundo, importantes transformações foram observadas nas relações econômicas internas, principalmente no que se refere ao mercado de trabalho. ${ }^{1}$

Vários estudos corroboram esta afirmação, Green et alii (2001) mostram que o período pós-abertura promoveu um crescimento substancial do retorno da educação no Brasil, indicando um crescimento da demanda por trabalho qualificado. Maia (2001), usando um modelo de insumo-produto, argumenta que a tecnologia decorrente do processo de abertura econômica destrói empregos dos trabalhadores não-especializados. Carneiro e Arbache (2003), a partir de um modelo de equilíbrio geral computável, concluem que há um aumento na demanda por trabalhadores qualificados. O estudo de Menezes Filho e Rodrigues Junior (2003) detectou um aumento na demanda do trabalho qualificado associado com uma maior intensidade tecnológica no setor manufatureiro brasileiro no período de 1994-1997.

Tais resultados são coerentes com o modelo proposto por Galor e Zeira (1993), Galor e Tsiddon (1997) e Birchenall (2001). Neste arcabouço teórico um choque tecnológico altera o perfil da demanda por trabalho incidindo sobre a mobilidade e distribuição de renda. Em períodos de maior progresso técnico a habilidade torna-se um fator dominante, de modo que há um estímulo na demanda por trabalho qualificado e, por conseguinte, um aumento na desigualdade salarial em relação os menos hábeis, produzindo uma concentração de renda. Este movimento interfere na decisão do agente em investir em capital humano, aumentando a mobilidade educacional e de renda. Vale salientar que este é um movimento de curto-prazo, quando as novas tecnologias se tornam mais acessíveis, a importância da qualificação declina, e o efeito familiar referente ao capital humano volta a prevalecer. ${ }^{2}$ Este movimento, no longo prazo, produz uma queda na mobilidade educacional e na desigualdade de salarial. ${ }^{3}$

A mobilidade de renda sugerida pelo modelo, ou seja, o crescimento de parcelas da população recebendo maiores e menores salários, é compatível com fenômeno de desaparecimento da classe média largamente comentada no Brasil pós-Plano Real. Entretanto, não se observou mudanças substanciais nos índices de desigualdade brasileiros no período considerado. ${ }^{4}$ Recentemente, diversos estudos têm considerado este paradoxo, podendo-se citar, entre outros, Jenkins (1995), Burtless (1997) e Burkhauser et alii (1999). De fato, as evidências contidas em Wolfson (1994) indicam que este processo de diminuição da classe média pode não ser detectada por medidas de desigualdade.

Para contornar este problema deve-se considerar o cálculo de medidas de polarização. Estas medidas foram propostas inicialmente por Esteban e Ray (1994) e Wolfson (1994). Em princípio, buscou-se discutir as vantagens desse tipo de mensuração frente às medidas de desigualdade e a sua pertinência na captação de aspectos sociais, econômicos e de mudanças políticas. ${ }^{5}$

\footnotetext{
${ }^{1}$ Ver Soares et alii (2001) e Gonzaga et alii (2006).

${ }^{2}$ Quando o efeito familiar é mais importante, passa a existir uma relação direta entre os anos de estudo dos pais e dos filhos.

${ }^{3}$ Tais relações são condizentes com Griliches e Mason (1972), Lenz e Laband (1989) e Juhn et alii (1993).

${ }^{4}$ De acordo com o Instituto de Pesquisa Econômica Aplicada (IPEA), o índice de Gini passou de 0,60 no ano de 1987 para 0,59 em 2002.

${ }^{5}$ Ver Quah (1997) e Milanovic (2000).
} 
Outro aspecto relevante quanto aos impactos da abertura econômica e suas conseqüências sobre a distribuição de renda no Brasil é sua heterogeneidade no tocante às suas regiões geográficas. Os trabalhos de Diniz (1995) e Saboia (2001) destacam a sensibilidade de setores industriais quanto ao processo de abertura e suas repercussões em termos espaciais. Saboia (2001), por exemplo, ressalta a maior sensibilidade do setor industrial frente a este processo, enfatizando seus efeitos diferenciados em termos regionais. Em suma, tais estudos sugerem que abertura econômica implicou em impactos regionalmente distintos nos setores industriais.

Desta forma, o objetivo deste estudo é investigar a natureza das mudanças na distribuição de renda do Brasil e de suas regiões no período de 1987 a 2003. Busca-se ainda identificar os fatores motivadores de tal transformação ressaltando os aspectos inerentes às mobilidades de renda e educacional.

Para tanto, aplica-se uma série de instrumentais estáticos e dinâmicos, onde se destacam: a) a estimação da medida de polarização de renda sugerida por Duclos et alii (2004) e; b) o cálculo das matrizes de transição proposto por Aebi et alii (2001). Isto posto, o artigo encontra-se dividido em cinco seções além dessa introdução. Na segunda seção discute-se o modelo teórico proposto por Galor e Zeira (1993), Galor e Tsiddon (1997) e Birchenall (2001). A terceira é destinada à apresentação dos métodos de inferência utilizados. Na quarta seção apresentam-se os resultados e na quinta seção às considerações finais.

\section{CAPITAL HUMANO E MOBILIDADE DE RENDA}

O modelo teórico aqui apresentado mostra a relação entre o espaço local, ou seja, o ambiente familiar e o ambiente global como determinantes na evolução da distribuição de capital humano, distribuição de renda e crescimento econômico. As implicações dinâmicas do modelo são: a) as condições iniciais determinam à evolução da distribuição de capital humano entre gerações, criando uma tendência à desigualdade no tocante a este processo e; b) as interações entre gerações e seus impactos sobre a estrutura produtiva podem conduzir a uma transformação qualitativa da dinâmica do sistema com múltiplos equilíbrios ou um equilíbrio único e globalmente estável. A distribuição de renda é transformada em uma variável "estado"que evolui dinamicamente. As implicações do ponto de vista empírico serão percebidas no tocante aos determinantes da mobilidade entre diferentes gerações que coexistam em cada período de tempo, como medida de variável "estado", e a mobilidade de distribuição como um todo ao longo do tempo.

\subsection{Ambiente Local: Efeito Familiar}

O modelo tem como base os artigos de Galor e Zeira (1993), Galor e Tsiddon (1997) e Birchenall (2001). Assume-se que há um continuum de gerações sobrepostas que vivem dois períodos com crescimento populacional zero. Os indivíduos de uma mesma geração e de gerações diferentes têm as mesmas preferências e são semelhantes quanto à produção de tecnologia de capital humano.

As preferências dos indivíduos são definidas ao longo de um vetor de consumo nos dois períodos de suas vidas, podendo ser representadas por uma função utilidade intertemporal $u^{t, i}=u\left(c_{t}^{t, i}, c_{t+1}^{t, i}\right)$, onde $c_{t}^{t, i}$ é o consumo do indivíduo $i$ da geração $t$ no período $j$.

No primeiro período de suas vidas os indivíduos são dotados com uma unidade de tempo o qual repartem entre a aquisição de capital humano e oferta de trabalho. A remuneração é dividida entre consumo e poupança. O salário $(w)$ tem relação direta com o nível de qualificação do indivíduo, o setor no qual ele trabalha e o setor no qual seus pais estão empregados.

No segundo período os agentes recebem a renda gerada por seus empregos $(w)$ e os ganhos herdados de seus pais no período anterior $(k)$ e decidem o quanto vão consumir e deixar para seus filhos que nascem sem qualquer qualificação. Os indivíduos tomarão decisão semelhante em períodos seguintes.

RBE Rio de Janeiro $\quad$ v. 61 n. 1/p. 7-32 Jan-Mar 2007 
Sem educação o agente se comporta como um trabalhador não-qualificado e recebe uma renda dada por:

$$
y(i)_{u . i}=w+(1+r) k(i)_{t}
$$

Caso decida investir em educação terá que assumir um custo fixo no período inicial, mas receberá um salário mais alto representado por um prêmio de trabalho resultante de sua mais alta produtividade,

$$
y(i)_{s . i}=w h_{i}+(1+r)\left[k(i)_{t}-e\right]
$$

O indivíduo decide investir em educação se a renda esperada com educação for maior que a renda esperada sem este investimento, mas esta decisão é influenciada por outros fatores. Na primeira situação é assumido que a dotação inicial é suficiente para custear o investimento em educação e, portanto, o agente poderia ser considerado um credor líquido. Neste caso o lado direito de 2 deverá ser maior que o lado direito de 1 a uma taxa de juros que satisfaça:

$$
h>1+\frac{(1+r) e}{w}=1+(1+r) b
$$

Esta igualdade é resultante da suposição adotada no modelo de que o custo de educação é uma proporção $(0<b<1)$ do salário. Se o agente obtém empréstimos para financiar sua educação, a condição 3 deve incluir uma maior taxa de juros de modo que assume a forma:

$$
h>1-\frac{k(i)\left[r^{*}-r\right]}{w}+\frac{1+r^{*} e}{w}=1-\frac{k(i)\left[r^{*}-r\right]}{w}+\left(i+r^{*}\right) b
$$

A decisão de investir ou não em educação, portanto, é influenciada pelo montante de dotação inicial que se herda dos pais e o prêmio futuro por qualificação ou anos de estudo. Se a herança é grande o suficiente para custear as despesas estudantis o agente sempre escolherá investir em educação, pois, apenas o prêmio de qualificação é que determinará sua decisão. Se o prêmio está acima de um nível dado por uma condição de não arbitragem (ver equação 3, a decisão será a mesma. No entanto, quando o agente precisa adquirir empréstimos para investir em educação o prêmio deixa de ser o único determinante da decisão de investimento em capital humano. Caso o lado direito de 4 seja negativo, a decisão de investir em educação independerá da herança deixada por seus pais. No entanto, se o prêmio está em um nível intermediário passará a existir um trade-off entre herança e prêmio por qualificação.

Para um agente se tornar indiferente entre ser educado ou não um menor prêmio deve ser compensado por uma maior herança. Quando o indivíduo se endivida para financiar sua educação sua riqueza se comporta como mostrado em 2 . Se for adicionada a esta equação a restrição orçamentária obtém-se um conjunto de possibilidades que pode ser melhor visualizado pela Figura 1.

A reta que se inicia no ponto $[w h, e]$ tem um maior coeficiente linear resultante de maiores custos para se investir em capital humano. A riqueza dos agentes pode ser representada pelas equações abaixo:

$$
W= \begin{cases}w+(1+r) k_{t} & k_{t}<k^{*} \\ w h_{t}+\left(1+r^{*}\left[k_{t}-e\right]\right. & k^{*} \leq k_{t}<e \\ w h_{t}+\left(1+r^{*}\right)\left[k_{t}-e\right] & k_{t} \geq e\end{cases}
$$

O problema do segundo período do agente pode ser representado através da seguinte maximização:

$$
\begin{aligned}
& \max _{\left\{c_{t}, k_{t+1}\right\}} U\left(c_{t}, k_{t+1}\right) \\
& \text { s.a. } c_{t}+k_{t+1}=W_{t}
\end{aligned}
$$


Figura 1 - Conjunto de Possibilidades

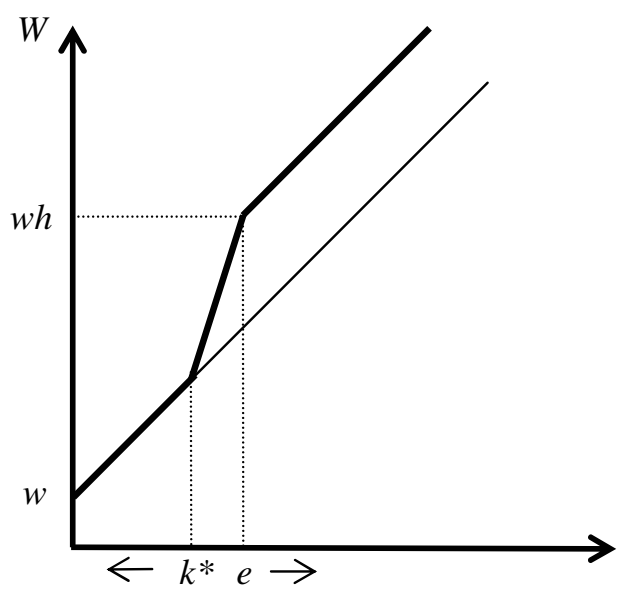

Fonte: Birchenall 2001

A riqueza é proveniente da equação 5 e será resultante da decisão de ser educado ou não no primeiro período. Sob as condições usuais a solução é um ponto de interior. Se for assumido uma função de produção Cobb-Douglas, o agente considerará sua riqueza em proporções fixas que depende do parâmetro $\gamma$ da função, ou seja:

$$
\begin{aligned}
c_{t} & =(1-\gamma) W_{t}\left(k_{t} ; r, r^{*}, h\right), \\
k_{t+1} & =\gamma W_{t}\left(k_{t} ; r, r^{*}, h\right)
\end{aligned}
$$

Sob tais condições, a dinâmica de cada geração passa a ser uma representação dada pela Figura 2.

A dinâmica ilustrada na Figura 2 apresenta a existência de três pontos de equilíbrio dos quais dois são estáveis. Os agentes que começam em uma condição inicial abaixo de $k^{*}$, trabalham como não qualificados assim como seus descendentes. O nível de capital ao qual eles convergirão é o $k_{1}$. Os agentes que começam com o nível de capital superior da $k^{*}$ podem ou não alcançar maiores níveis de renda dependendo do acesso a educação. Os que possuem uma dotação inicial maior, ou seja, tenham uma maior herança, convergirão para um maior nível de riqueza $\left(k_{3}\right)$ e todos os seus descendentes poderão investir em educação. A distribuição de renda tende a ser não ergódica e a se polarizar em dois grupos de renda um grupo de ricos e outro de pobres, os quais se reproduzirão geração após geração.

As transformações pelas quais passou a economia brasileira sugerem um aumento da demanda relativa por trabalho qualificado. As mudanças técnicas resultantes do processo de abertura foram intensivas em trabalho especializado. Considerando que os indivíduos não qualificados estão sujeitos à restrição orçamentária, ou seja, tendem a ter uma baixa dotação inicial de recursos, tal cenário sugere que os pobres tendem a permanecer pobres, o que implicará em uma polarização de renda. Dado que o processo de reformas estruturais conduz a uma polarização da distribuição de renda, não deve ser deixado de lado o papel do prêmio por educação $(h)$ na determinação da decisão de ser educado ou não devido ao seu trade-off com a variável taxa de juros. 
Figura 2 - Dinâmica do Capital

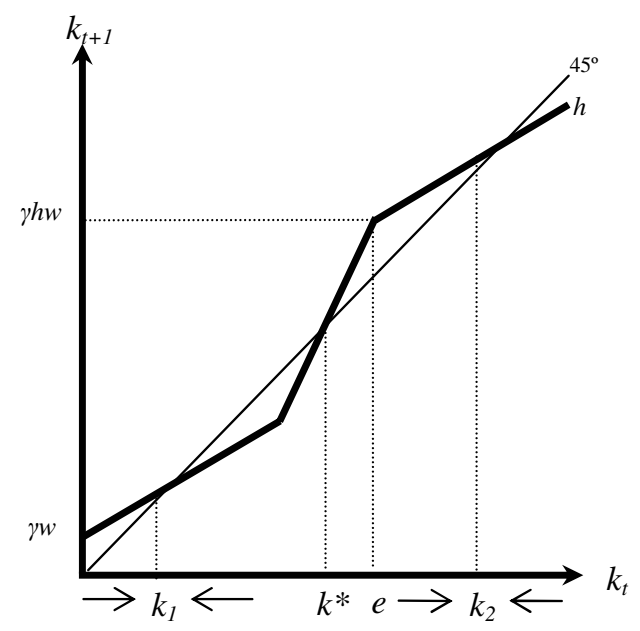

Fonte: Birchenall 2001

\subsection{Ambiente Global: Fatores Externos}

A população será distribuída em dois grupos de trabalhadores qualificados e não qualificados de acordo com as características da economia e o prêmio educacional, ou seja, a massa total de trabalhadores é representada por:

$$
\begin{aligned}
& L_{t}=L_{u, t}+L_{s, t}, \\
& \int_{\left[0, k^{*}\right]} f_{u}(t, x) d x+\int_{\left[k^{*}, \infty\right]} f_{s}(t, x) d x
\end{aligned}
$$

Apesar da premissa de população constante, as densidades dos dois grupos dependem do tempo, dado que existem indivíduos migrando entre os grupos e para os quais será equilíbrio de longo prazo ser educado ou cair na armadilha de pobreza. Do mesmo modo se pode calcular a distribuição de renda para cada período de tempo, como mostrado abaixo:

$$
Y_{t}=\int_{\left[0, k^{*}\right]} g_{u}(t, z) d z+\int_{\left[k^{*}, \infty\right]} g_{s}(t, z) d z
$$

Onde, $g$ é a densidade de cada grupo de agentes. Para assegurar o crescimento sustentado na economia além do crescimento dependente de riqueza se considerou a taxa de crescimento de capital humano endógeno e dependente da fração $\varphi$ que representa a proporção de trabalhadores qualificados na economia e o efeito da complementaridade do capital físico total.

$$
h= \begin{cases}\left\{L_{s, t}\right\}^{\phi}\left\{K_{t}\right\}^{1-\phi}=\left\{\int_{[0, k *]} f_{s}(t, z) d z\right\}^{\phi} K_{t}^{1-\phi} & , \text { para } K_{t} \geq \bar{K} \\ h_{t-1} & , \text { caso contrário }\end{cases}
$$

A idéia central é a de que o capital humano é constante exceto para uma região limiar, além da qual ele cresce rapidamente conduzindo a um grande diferencial salarial. Pode-se pensar que este intervalo 
entre crescimento zero e crescimento alto se dá onde o capital físico atinge uma massa crítica que sustenta o processo de desenvolvimento econômico. A equação 8 mostra a conexão entre mobilidade e decisões dinâmicas agregadas, enquanto que 7 mostra a composição estática da distribuição de renda, apesar das densidades serem função do tempo.

Sob este esquema a taxa de crescimento do estoque de capital humano poderia ser suficientemente alta para assegurar que um padrão não ergódico de crescimento possa ser revertido e, à medida que o tempo passa, uma melhoria na distribuição de renda possa ser alcançada.

Os incentivos inerentes, em um nível de capital humano mais alto provocam uma mudança substancial na acumulação de capital e na decisão de investimento em capital humano. A um dado estoque de capital humano menor que $h_{1}$ não existem incentivos para se investir em educação (ver Figura 3), logo as gerações futuras atingirão nível de equilíbrio A. Para o estoque de capital humano $h_{2}$ alguns membros decidem estudar, mas ao longo prazo as gerações futuras convergirão para o mesmo nível A dado que os incentivos não serão suficientemente altos para fornecer uma dotação que assegure a educação para todas as gerações, caracterizando assim a armadilha da pobreza. No caso $h_{3}$, os agentes têm dotação inicial suficiente para escolherem estudar. $\operatorname{Em} h_{4}$ os agentes apresentam uma situação onde o incentivo a ser educado conduz ao estado estacionário onde todos decidem investir em capital humano. Em $h_{5}$, o estoque de capital humano é tão grande que a decisão não depende do nível de riqueza inicial o que neutraliza o efeito familiar.

O capital humano inicial não é, portanto, o único determinante do desenvolvimento econômico. A composição do capital humano é o elemento chave neste cenário. No longo prazo a distribuição de capital humano perde sua dependência das condições iniciais e supera o efeito familiar, ou seja, o efeito da externalidade local.

Figura 3 - Dinâmica de Renda e Capital Humano Generalizado

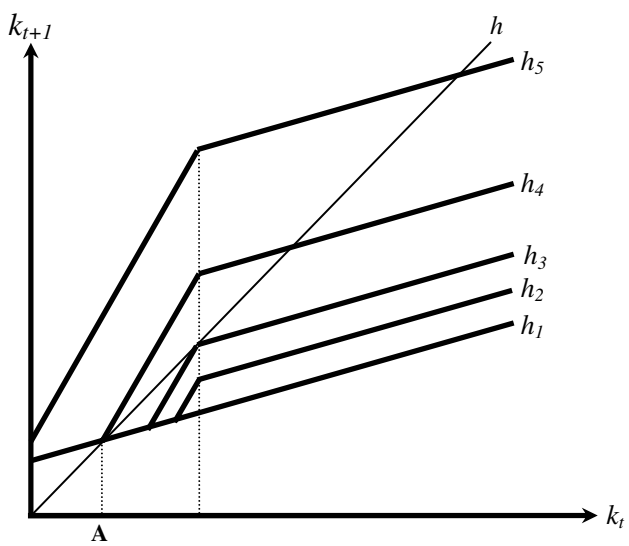

Fonte: Birchenall 2001

Em suma, o modelo sugere que nos períodos onde o progresso tecnológico é mais intenso a importância relativa do ambiente familiar diminui e a mobilidade e a desigualdade crescem. Dado um choque tecnológico, há um aumento no prêmio por qualificação que impulsiona a mobilidade educacional decorrente da diminuição do efeito familiar. Este efeito tecnológico, portanto, em um primeiro momento aumenta a desigualdade salarial em favor dos mais qualificados e estimula a acumulação de capital humano. 
Admitindo um estágio de desenvolvimento onde o efeito de externalidade local cessa, se tem uma polarização na distribuição de renda enquanto que em períodos onde o efeito agregado é dominante passa a existir uma tendência de convergência. $O$ modelo aqui apresentado sugere um trade-off entre igualdade e persistência no longo prazo, associado a uma desigualdade no curto prazo, precedidas por períodos de prosperidade e menor persistência na sociedade. Uma distribuição desigual de capital humano é necessária para aumentar a média de capital humano e o produto durante o estágio inicial de desenvolvimento.

\section{MÉTODOS DE INFERÊNCIA}

Nesta seção serão apresentados os principais métodos de estimação adotados na análise. No primeiro tópico se discute as medidas de polarização e sua relação com os índices de desigualdade. Em um segundo momento, apresenta-se a medida de polarização proposta por Duclos et alii (2004). Em seguida, se discute o método para estimação de matrizes de transição de probabilidade a partir de dados de corte contidos em Aebi et alii (2001). Outras inferências também serão utilizadas, no entanto, suas apresentações serão omitidas por se considerar que estes métodos já se encontram consolidados na literatura empírica. ${ }^{6}$

\subsection{Polarização e Desigualdade}

Os resultados da seção 2 sugerem que o processo de abertura econômica pode promover um movimento de renda caracterizado pela polarização. No entanto, qual a relação desse novo conceito com as medidas de desigualdade? Geralmente, as discussões acerca do desaparecimento da classe média carregam a impressão equivocada de que polarização e desigualdade caminham sempre na mesma direção. ${ }^{7}$ Normalmente o desaparecimento da classe média está relacionado a observações empíricas de esvaziamento das faixas de renda intermediárias, associadas ao aumento da participação dos estratos mais baixos e mais altos. Tais observações sugerem que este esvaziamento de renda pode implicar em uma tendência bi-modal em sua distribuição. Os impactos das mudanças no formato da distribuição e seus rebatimentos no tocante as medidas de dispersão são o ponto central da análise aqui exposta. A observação teórica básica é a de que a polarização deve ser entendida de um modo diferenciado do conceito de desigualdade.

A ilustração sugerida por Wolfson (1994), representada pela Figura 4, pode tornar essa idéia mais clara. Note que a figura traz duas funções densidades hipotéticas. A primeira representada pela linha tracejada é uniformemente distribuída ao longo do intervalo de 0,25 a 1,75. A segunda distribuição, ilustrada por uma linha sólida, é derivada da densidade uniforme a partir de transferências preservadoras da média sendo claramente bi-modal. Conseqüentemente, a última densidade é mais polarizada que a anterior.

Contudo, a densidade bi-modal foi construída de modo que qualquer medida de desigualdade seja consistente com o critério de Lorenz, ou seja, ela será menos desigual. Em outras palavras, esta densidade possui uma curva de Lorenz mais próxima da linha de 45 graus em relação à uniforme. Isto se deve ao fato de que a distribuição bi-modal pode ser "derivada"de uma distribuição uniforme por dois conjuntos de transferências redistributivas preservadoras da média seguindo os critérios de Atkinson (1970). Logo, um decréscimo da desigualdade pode estar, na verdade, indicando um aumento na polarização de renda.

\footnotetext{
${ }^{6}$ Como é o caso das funções de densidade kernel, índices de desigualdade, modelo de pseudo painel e as matrizes de transição markovianas.

${ }^{7}$ Ver, por exemplo, Blackburn e Bloom (1985).
} 


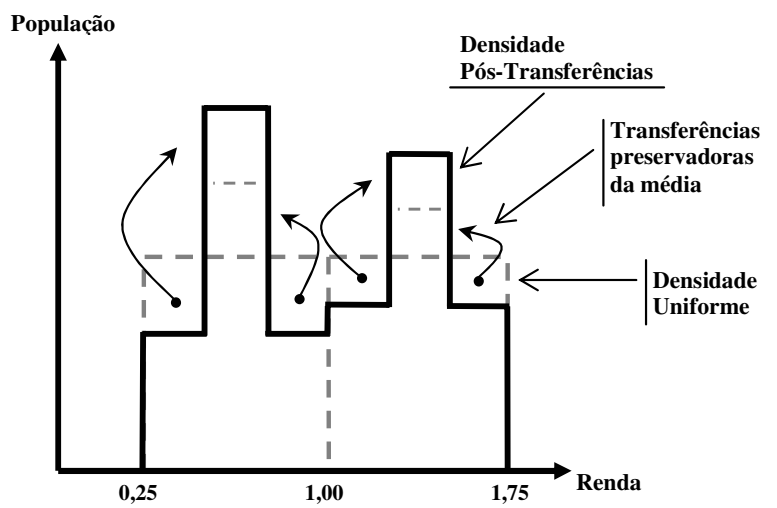

Fonte: Wolfson (1994)

\subsection{Medida de Polarização de Renda}

O conceito de polarização está relacionado, em um contexto geral, às noções de "identificação"e "alienação". De uma forma mais objetiva, suponha que devido a fatores de "identificação"a população de indivíduos se divida em dois grupos sociais distintos $x$ e $y^{8}$. Assume-se uma relação de proximidade entre os indivíduos de cada grupo. No entanto, esta proximidade não será observada entre os componentes do grupo $x$ e os de $y$. existirá entre eles uma espécie de competição salarial, ou seja, cada grupo buscará ampliar o grau de "alienação"de renda em detrimento do outro. Logo, um indivíduo localizado no grupo $x$ sentirá a alienação vis-à-vis o outro localizado em $y$, a partir da distância Euclidiana $|x-y|$. Em uma função de densidade de renda $f$ esse antagonismo poderá ser representado por:

$$
T(i, a)
$$

Onde, $i=f(x) ; a=|x-y| ; T$ é crescente no segundo argumento e; $T(i, 0)=T(i, a)=0$. Note que, intuitivamente, em uma função de densidade $\mathrm{f}$ o grau de "identificação"estará relacionado ao tamanho dos "picos"da distribuição, enquanto que a "alienação"se referirá à distância entre estes "picos". Dessa forma, o grau de polarização de renda de uma sociedade poderá ser representado pela "soma"de todos os antagonismos existentes:

$$
P(F)=\iint T(f(x),|x-y|) f(x) f(y) d x d y
$$

Sob estas considerações, Esteban e Ray (1994) propõem a mensuração do índice de polarização a partir do número e do tamanho dos "picos"observados na função de densidade de renda. Porém, em um estudo recente Duclos et alii (2004) - DER - apontam as limitações desta mensuração ${ }^{9}$ e apresentam uma alternativa relativamente mais robusta.

Em DER a determinação do número de grupos aos quais os indivíduos pertencem, é realizada nãoparamétricamente a partir de funções kernel. Dessa forma, o estimador para o índice de polarização

${ }^{8}$ Vale ressaltar que neste estudo noção de "identificação"estará ligada ao nível de qualificação dos indivíduos, ou seja, grupo de trabalhadores qualificados e não-qualificados.

${ }^{9}$ As críticas referem-se principalmente à sua descontinuidade 
será dado pela substituição função de distribuição teórica por uma função empírica. Sob a hipótese de uma distribuição de renda aleatória i.i.d., obtém-se um estimador com distribuição limite normal sem, no entanto, impor suposições sobre a distribuição "verdadeira"da amostra.

\subsubsection{Estimação}

Sob algumas considerações e axiomas ${ }^{10}$, define-se a medida de polarização por:

$$
P_{\tau}(F)=\int_{y} f(y)^{\tau} a(y) d F(y)
$$

Onde, $y$ corresponde à renda; $F$ a função de distribuição associada à densidade $f$ e à média $\mu$; $\tau \in(0.25,1)$ ao parâmetro de threshold; $a(y) \equiv \mu+y[2 F(y)-1]-2 \int_{-\infty}^{y} x d F(x)$. É importante ressaltar que se $\tau=0$, (9) tornar-se-á um índice de Gini.

Supõe-se que $P(F)$ é estimada usando uma amostra aleatória $n$ observações de renda $i . i . d$. extraída da distribuição $F(y)$ e ordenada de forma a $y_{1} \leq y_{2} \leq \ldots \leq y_{n}$. O estimador $P_{\tau}(\hat{F})$ será obtido a partir das substituições da: a) função de distribuição $F(y)$ por uma distribuição empírica $\hat{F}(y)$; b) densidade $f(y)^{\tau}$ por seu estimador $\hat{f}(y)^{\tau}$ e; c) $a(y)$ por $\hat{a}(y)$. Sendo assim:

$$
P_{\tau}(\hat{F})=n^{-1} \sum_{i=1}^{n} \hat{f}\left(y_{i}\right)^{\tau} \hat{a}\left(y_{i}\right)
$$

onde,

$$
\hat{a}\left(y_{i}\right)=\hat{\mu}+y_{i}\left[n^{-1}(2 i-1)-1\right]-n^{-1}\left(2 \sum_{j=1}^{i-1} y_{j}+y_{i}\right)
$$

Onde, $\hat{\mu}$ é a média amostral e $\hat{f}\left(y_{i}\right)^{\tau}$ é obtido não-paramétricamente utilizando um estimador kernel simétrico de modo a: $\int_{-\infty}^{+\infty} K(u) d u=1$ e $K(u) \geq 0$. Sendo assim, define-se $\hat{f}(y) \equiv n^{-1} \sum_{i=1}^{n} K_{h}(y-$ $\left.y_{i}\right)$, com $K_{h}(z) \equiv h^{-1} K\left(\frac{z}{h}\right)$ e $h$ correspondendo ao parâmetro de suavização. ${ }^{11} \mathrm{O}$ parâmetro ótimo $h^{*}$ será obtido de modo a minimizar o erro quadrático médio do estimador, ou seja:

$$
h^{*} \cong 4.7 n^{-0.5} \sigma \tau^{0.1}
$$

Onde, $\sigma$ corresponde à variância da renda. Por fim, observa-se que sob certas condições de regularidade: ${ }^{12}$

$$
n^{0.5}\left[P_{\tau}(\hat{F})-P_{\tau}(F)\right] \stackrel{L}{\rightarrow} N\left(0, V_{\tau}\right)
$$

com,

$$
V_{\tau}=\operatorname{var}_{f(y)}\left((1+\tau) f(y)^{\tau} a(y)+y \int f(x)^{\tau} d F(x)+2 \int_{y}^{\infty}(x-y) f(x)^{\tau} d F(x)\right)
$$

Sendo assim, o índice de polarização será livre de imposições a respeito da distribuição original da amostra podendo ser estimado consistentemente. Logo, $P_{\tau}(F)$ constitui uma medida geral, consistente e não-viesada dada à escolha pertinente para o estimador da densidade $f(y)$ e de seu respectivo parâmetro de suavização.

\footnotetext{
${ }^{10}$ Fazem-se considerações sobre o espaço de densidades e as transformações preservadoras de média squeeze. Postulam-se quatro axiomas relacionados à transformação squeeze e à propriedade da invariância populacional. Para detalhes ver a seção 2.2 de Duclos et alii (2004, p.1741).

${ }^{11}$ Vale salientar que o processo de estimação considera uma função kernel gaussiana (contínua e diferenciável), dada por: $K(u)=$ $(2 \pi)^{-0.5} \exp ^{-0.5 u^{2}}$

$12 " \stackrel{L}{\rightarrow}$ "corresponde à convergência em distribuição. Para maiores detalhes ver Pollard (1984).
} 


\subsection{Dinâmica de Renda em Dados de Corte}

A análise da dinâmica de renda brasileira apresenta pelo menos um problema: não se tem a informação relativa a cada indivíduo ano a ano. Ou seja, nos dados referentes à renda pessoal da Pesquisa Nacional de Amostras por Domicílios (PNAD), o indivíduo na posição $i$ no vetor do ano base (1987), não será o mesmo indivíduo na posição no vetor do ano final (2003). O que se dispõe são as informações percentuais referentes ao número de pessoas dentro de cada extrato de renda nos diversos anos considerados. No entanto, pode-se a partir dessa base de informação, inferir aspectos de mobilidade dinâmica dentro dos diversos estratos.

Aebi et alii (2001) demonstram a possibilidade de se extrair informação dinâmica de dados de corte, utilizando-se apenas de dois vetores no tempo $q_{t}$ e $q_{s}$ com $s>t$. Para tanto, define-se uma função de densidade bi-dimensional $F=\left(f_{i j}\right)_{i, j=1, \ldots, k}$, onde, $f_{i j}$ denotará a probabilidade do indivíduo estar na classe $i$ no período inicial $(t)$ e migrar para a classe $j$ no período final $(s)$. Sendo assim, a densidade $F$ será o produto de uma distribuição arbitrária $\pi$ e uma matriz de transição $P$ :

$$
F=\operatorname{diagonal}(\pi) P
$$

Onde, o operador diagonal $(g)$ transforma o vetor $k \times 1$ em uma matriz $k \times k$. Normalmente, a função $F$ não é compatível com as distribuições $q_{t}$ e $q_{s}$. No entanto, se propõe um ajustamento nesta função de modo a torná-la compatível com as distribuições observadas. Dessa forma, a $F$-ajustada $\left(F^{*}\right)$ deverá satisfazer as restrições inicial e final, ou seja:

$$
q_{t}=F^{*} t \mathrm{e} q_{s}=\left(F^{*}\right)^{\prime} t
$$

Onde, $t$ representa um vetor unitário $k \times 1$. Sob estas condições, os autores propõem uma escolha de $P$ de modo que a densidade ajustada $F^{*}$ minimize a entropia relativa:

$$
F^{*}=\operatorname{argmin}_{G=g_{i j} \in \zeta} H(G \mid F)=\operatorname{argmin}_{G=g_{i j} \in \zeta} \sum_{i, j=1}^{k} g_{i j} \log \left(\frac{g_{i j}}{f_{i j}}\right)
$$

Onde, $\zeta$ corresponde ao espaço de densidades bidimensionais e $H(g F)$ à entropia relativa nãonegativa e estritamente convexa de modo a fornecer soluções únicas para o problema de minimização. Tal solução poderá ser computada a partir de critérios interativos como interative proportional fitting procedure (IPFP). A Matriz de transição resultante desse processo pode ser expressa por:

$$
\begin{array}{r}
P^{*}=\Phi_{s}^{-1} P \Phi_{s} \text { com, } \\
\Phi_{s}=\operatorname{diagonal}\left(\hat{\phi}_{1, s}, \ldots, \hat{\phi}_{k, s}\right)=\operatorname{diagonal}\left(\sum_{j=1}^{k} p_{1, j} \phi_{j, s}, \ldots, \sum_{j=1}^{k} p_{k, j} \phi_{j, s}\right), \\
\Phi_{s}=\operatorname{diagonal}\left(\phi_{1, s}, \ldots, \phi_{k, s}\right)
\end{array}
$$

Onde, $\phi$ 's correspondem aos multiplicadores de Schrödinger. ${ }^{13}$ Note que os multiplicadores ajustaram a matriz de modo a torná-la compatível com as restrições (10). Destaca-se ainda que só os multiplicadores relacionados à condição final é que interferem no ajustamento da matriz de transição de probabilidade.

A implementação do processo inicia-se com a escolha de uma matriz de transição hipotética. Uma alternativa é considerar que $P$ possui mobilidade máxima. ${ }^{14}$ Normalizando $\phi_{1, t}=\phi_{1, s}$ e assumindo

\footnotetext{
${ }^{13}$ Para detalhes ver também Aebi e Nagasawa (1992).

${ }^{14}$ Utilizando, por exemplo, as medidas de mobilidade propostas por Shorrocks (1978) e Geweke et alii (1986).
} 
$\pi=q_{t}$, obtêm-se os multiplicadores de Schrödinger por: $\phi_{1, t}=\sqrt{q_{1, s} / q_{1, t}}$ e $\phi_{j, s}=\sqrt{q_{1, t} / q_{1, s}} \times$ $\left(q_{j, s} / q_{j, t}\right)$. A análise dos multiplicadores é relativamente simples. Valores iguais a um indicam que as probabilidades da matriz de transição $P$ não necessitam de ajuste. No entanto, valores maiores ou menores do que um, significam que as probabilidades de $P$ deverão ser maiores ou menores para que ela satisfaça 10. Logo, a observação desses multiplicadores fornecerá uma informação importante em relação à mobilidade de cada estrato de renda.

\section{RESULTADOS}

Neste tópico, a variável "renda real de todos os trabalhos"assume o papel central e, assim como as informações relativas aos "anos de estudo", são oriundas da Pesquisa Nacional de Amostras por Domicílios (PNAD) $)^{15}$, realizada pelo Instituto Brasileiro de Geografia e Estatística (IBGE) tendo como base o mês de setembro dos respectivos anos. Cada informação anual compreende cerca de 100.000 observações familiares e 330.000 pessoais.

Figura 5 - Densidade de Renda Relativa no Brasil (a) 1987 e (b) 2003

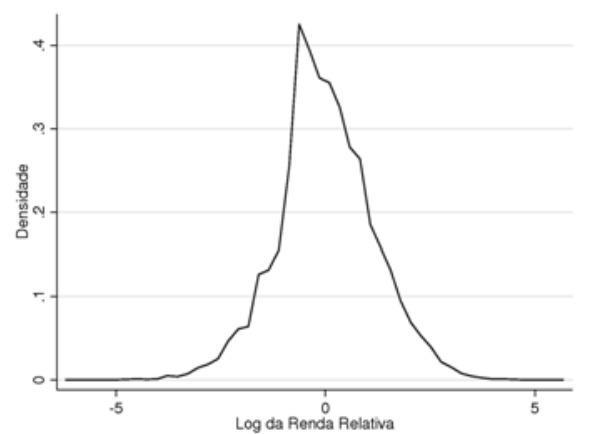

a

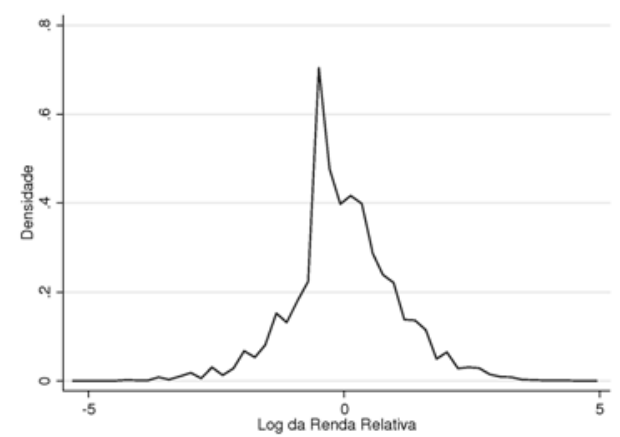

b

\subsection{Distribuição de Renda: Concentração e Polarização}

O cálculo das densidades kernel tem sido freqüentemente utilizado em investigações relativas à mudança no padrão de distribuição de renda pessoal. Podendo-se citar, entre outros, Jenkins (1995) e Burkhauser et alii (1999). Sendo assim, toma-se a estimação destas densidades como ponto de partida para a investigação do padrão de distribuição de renda no Brasil.

A Figura 5 apresenta as funções de densidade $k e r n e{ }^{16}$ para a renda relativa do Brasil nos anos de 1987 e 2003. Observa-se claramente uma mudança em seu padrão distributivo no período considerado. A primeira impressão é de que a densidade para o ano de 1987 se caracteriza por um comportamento uni-modal evoluindo em 2003 para uma representação bi-modal. Em segundo lugar, nota-se um squeeze

\footnotetext{
${ }^{15}$ Vale salientar que a pesquisa apresenta algumas descontinuidades no período considerado.

${ }^{16}$ Optou-se pela função kernel Epanechnikov representada por: $K=3 / 4\left(1-u^{2}\right) I(|u| \leq 1)$. Onde, $u$ é o argumento da função kernel e $I$ a variável de indicador que assume valor um se o argumento é verdadeiro e zero caso contrário. O parâmetro de suavização foi escolhido de acordo com a regra prática de Silverman (1986).
} 
(estreitamento) e uma maior quantidade de "picos"na densidade de 2003 (Figura 5.b). Tais características podem indicar: a) uma redução da desigualdade associada a uma aparente redução da dispersão e; b) a formação de dois grupos de renda recebendo, um salários abaixo e o outro acima do nível médio o que, como destacado nas seções 2 e 3, pode estar relacionado à "identificação"desses indivíduos em grupos de trabalhadores qualificados e não-qualificados.

No contexto regional observa-se a mesma tendência embora com graus de intensidade diferenciados. Na Figura 6 são apresentadas às distribuições para a região Nordeste cuja densidade referente ao ano de 2003 apresenta um maior número de "picos"e um formato ligeiramente mais afilado que o de 1987. A Figura 7 mostra um caso onde o formato da distribuição não se altera de modo expressivo. A região Sul, no tocante ao formato de sua densidade, foi a que apresentou as menores mudanças em relação aos seus períodos inicial e final.

Figura 6 - Densidade de Renda Relativa na Região Nordeste: (a) 1987 e (b) 2003

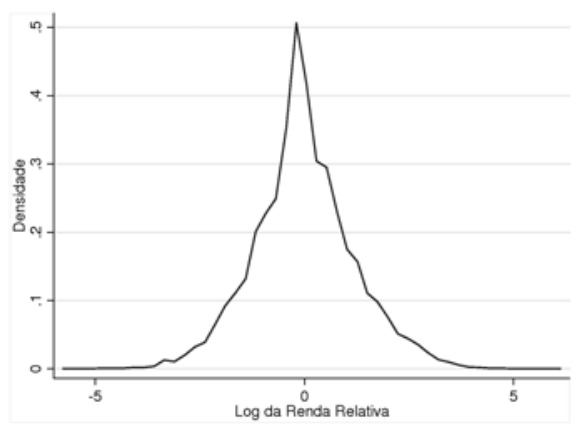

a

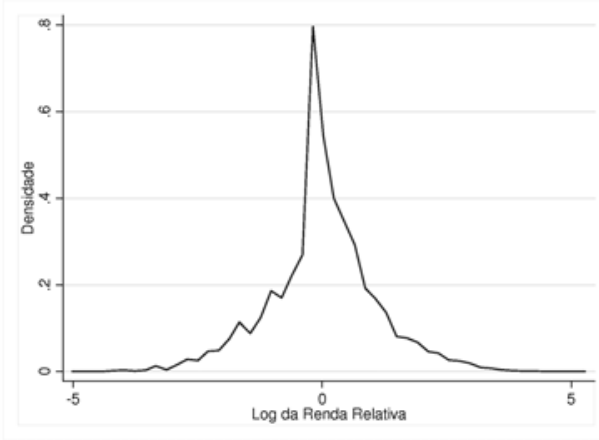

b

Figura 7 - Densidade de Renda Relativa Região Sul (a) 1987 e (b) 2003

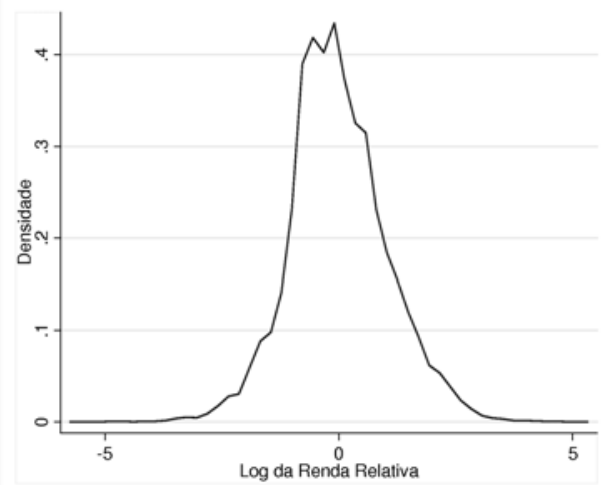

a

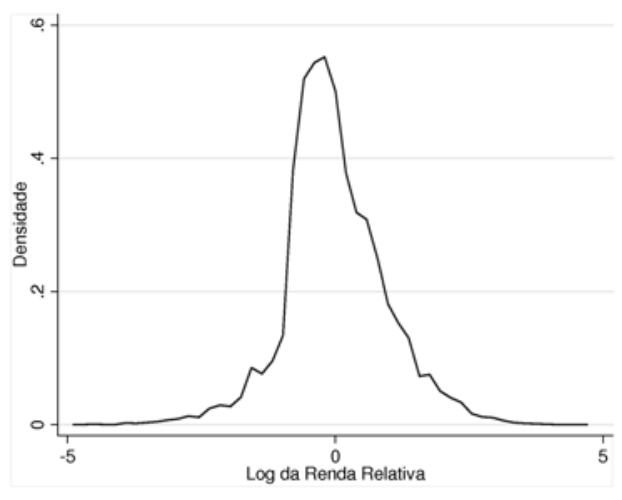

b 
De fato, o aparente squeeze detectado visualmente nas funções de densidade é confirmado pelo cálculo dos índices de Gini. Como pode ser observado na Figura 8, apesar de seu comportamento razoavelmente estável, observa-se uma pequena redução da desigualdade de renda tanto para o Brasil como para todas as regiões. Vale ressaltar que as regiões Nordeste e Sul são as que apresentam, respectivamente, os maiores e menores índices de desigualdade.

Figura 8 - Evolução do Índice de Gini - Brasil e Regiões

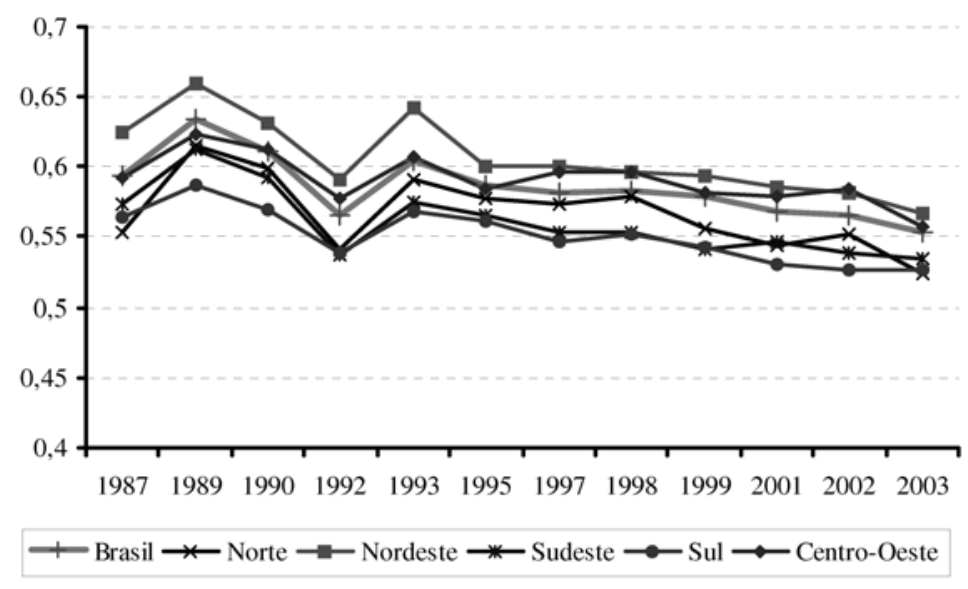

Fonte: Dados da pesquisa.

No entanto, como já destacado, entre outros, por Jenkins (1995) e Burtless (1997) as medidas de desigualdade são incapazes de captar aspectos importantes no padrão das distribuições de renda. Podese dizer que o índice de Gini não elucida as transformações relevantes na distribuição de renda tanto caso do Brasil como de suas regiões. A formação de "picos", bem como a evolução para uma distribuição bi-modal (Figura 5.b) podem produzir importantes vieses nas medidas de desigualdade (ver seção 3.1).

Tal constatação lança um olhar crítico sobre os resultados relativos ao índice de Gini. Como já ressaltado anteriormente, fenômenos relativos ao desaparecimento da classe média - largamente comentados no Brasil pós-Plano Real - podem não estar sendo captados pelos índices de desigualdade. Isso posto, o cálculo das medidas de polarização se faz necessário. Pressupõe-se que a criação de grupos de renda, sugerida pela observação das funções kernel, indica um aumento no grau de polarização da renda nacional. Optou-se pela estimação da medida de polarização "robusta"proposta por Duclos et alii (2004). Valores próximos a um (zero) representam uma alta (baixa) polarização.

Como pode ser observado na Figura 9 o Brasil e regiões apresentam um aumento significativo no seu índice de polarização. No entanto, podem ser destacados três períodos no tocante a trajetória deste indicador: o primeiro refere-se ao intervalo 1987-1995, onde se observa um crescimento paulatino da polarização; o segundo que se estende de 1995-1999, é marcado por um decréscimo deste índice e; o trecho final de 1999-2003 marca uma retomada no seu crescimento.

Em termos regionais, no primeiro período, verifica-se um aumento expressivo no indicador de polarização do Sudeste brasileiro. Tal comportamento pode estar relacionado com as repercussões do processo de abertura econômica e sua relação mais íntima com os setores industriais, mais concentrados nesta área geográfica. $O$ processo de abertura econômica no Brasil está associado a choques tecnológicos nos setores industriais. Logo, o aumento da polarização poderia estar associado ao aumento do prêmio por qualificação decorrente do crescimento da demanda por trabalho qualificado, como sugerido pelo mo- 
delo teórico, o que aumenta a concentração de renda inicialmente. No segundo período, no entanto, o Sudeste perde o posto de região com maior polarização de renda, sugerindo o arrefecimento dos efeitos do processo de liberalização comercial.

A partir de 1997, ou seja, no terceiro período de destaque, o Nordeste passa a apresentar o maior índice de polarização de renda regional, comportamento este digno de nota dado que, por ser uma região à margem do processo de industrialização, não se encaixa na previsão do modelo teórico. As demais regiões apresentam trajetória e valores absolutos bastante próximos ao longo de todo período analisado.

Figura 9 - Evolução do Índice de Polarização - Brasil e Regiões

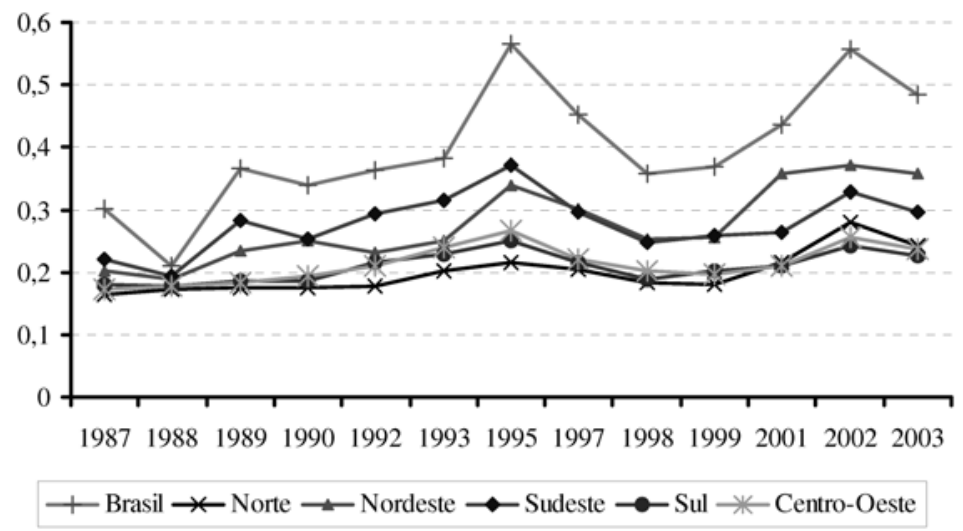

Fonte: Dados da pesquisa. Parâmetro de threshold $\tau=1$

Em linhas gerais, o comportamento observado no Gráfico 2 indica que o período em análise foi marcado por um processo de mobilidade de renda. Mais especificadamente, conforme já discutido na seção metodológica, o aumento de polarização no Brasil sugere um aumento da concentração de indivíduos em determinadas faixas de renda em detrimento das restantes. No entanto, o índice per si não permite identificar quais as faixas de renda afetadas por este movimento. A seção seguinte será destinada ao esclarecimento deste ponto.

\subsection{Dinâmica de Renda}

A análise aqui proposta tem como ponto de partida a construção dos vetores de freqüência de renda para os anos de 1987 e 2003. Para tanto, considerou-se a freqüência relativa de indivíduos dentro de cada estrato de renda real (Tabela 1). Em uma primeira inspeção visual, constata-se que o Brasil apresentou uma redução dos estratos de renda 3, 4 e 5 associados a um aumento das faixas 1 e 6 . Esta tendência indica que a polarização está se dando com maior intensidade na menor e maior faixa de renda. Este processo é coerente com a noção de desaparecimento das classes intermediárias de renda, já ressaltado em tópicos anteriores.

Observou-se para todas as regiões uma queda da participação das faixas de renda 3 e 4 exceto para o Centro-Oeste que cai apenas na faixa 3, enquanto que o indicador da faixa 4 permanece estável. Na região Sudeste, há um aumento expressivo da faixa 2 e incrementos moderados das faixas 5 e 6 . Os estratos de renda 3 e 4 tiveram redução considerável em sua parcela total. A região Nordeste apresentou um forte aumento do primeiro estrato de renda em detrimento, sobretudo das faixas 3 e 4 . 
Erik de Figueirêdo, José Luis Junior, Sabino da Silva Porto Junior

Tabela 1 - Percentual de Pessoas por Classe de Renda . Brasil e Regiões

\begin{tabular}{lcccccc}
\hline \multicolumn{7}{c}{$1987(\%)$} \\
\hline Classes de Renda (R\$) & Brasil & Norte & Nordeste & Sudeste & Sul & Centro-Oeste \\
\hline (1) $0-260$ & 21,21 & 11,76 & 38,68 & 14,81 & 13,91 & 16,16 \\
(2) $261-520$ & 26,2 & 24,26 & 27,35 & 24,29 & 26,24 & 29,68 \\
(3) 521-1164 & 30,44 & 37,23 & 20,28 & 34,76 & 34,95 & 30,74 \\
(4) $1165-5000$ & 19,81 & 24,1 & 12,18 & 23,54 & 22,49 & 20,32 \\
(5) 5001-10000 & 1,91 & 2,23 & 1,27 & 2,16 & 1,92 & 2,38 \\
(6) Acima de 10000 & 0,43 & 0,43 & 0,24 & 0,44 & 0,49 & 0,71 \\
\hline \multicolumn{7}{c}{$2003(\%)$} \\
\hline Classes de Renda (R\$) & Brasil & Norte & Nordeste & Sudeste & Sul & Centro-Oeste \\
(1) 0-260 & 25,18 & 25,01 & 47,31 & 14,76 & 13,66 & 17,75 \\
(2) 261-520 & 29,4 & 34,38 & 26,21 & 29,81 & 30,26 & 30,69 \\
(3) 521-1164 & 25,94 & 23,97 & 16,14 & 31,85 & 32,02 & 25,85 \\
(4) 1165-5000 & 17,07 & 14,97 & 9,15 & 20,74 & 21,56 & 20,99 \\
(5) 5001-10000 & 1,82 & 1,46 & 1,01 & 2,31 & 1,95 & 2,54 \\
(6) Acima de 10000 & 0,6 & 0,2 & 0,19 & 0,53 & 0,56 & 2,18 \\
\hline
\end{tabular}

Fonte: Dados da pesquisa.

Do ponto de vista dinâmico, considerou-se a análise dos multiplicadores de Schrödinger. Optou-se, pela hipótese da matriz de transição com mobilidade máxima (ver seção 3.3). Os resultados contidos na Figura 10 reforçam as observações já feitas no tocante à dinâmica dos estratos de renda contidos na Tabela 1. As probabilidades de movimento nas faixas 1, 2 e 6 aumentaram, contrabalançado com a sua redução nas faixas 3, 4 e 5 . Nas regiões Norte e Nordeste tem-se um decréscimo de todas as faixas de renda associadas a um aumento da faixa 1 . No Centro-Oeste as cinco primeiras faixas de renda apresentam uma dinâmica estável, enquanto que a sexta é a única que apresenta um aumento. Já nas regiões Sudeste e Sul as faixas 2, 5 e 6 aumentam tendo como contrapartida um decréscimo das faixas 3 e 4 .

A análise efetuada nesta seção permite uma melhor caracterização do processo de polarização de renda. Os movimentos nas faixas de renda se deram no sentido de enfraquecimento das faixas intermediárias, o que reforça a idéia de desaparecimento da classe média em detrimento, mais fortemente, das classes mais baixas e mais altas. Regionalmente, destaca-se a mobilidade do Nordeste onde houve um aumento significativo do primeiro estrato de renda em detrimento dos demais. Tais resultados somados as conclusões referentes à medida de polarização conduzem a seguinte conclusão: houve uma mudança não negligenciável na distribuição de renda brasileira no período considerado.

Portanto, o comportamento da renda se adequa ao que foi previsto pelo modelo teórico proposto. No entanto, ressalvas devem ser feitas quanto ao encaixe do modelo em relação às especificidades econômicas regionais. A tendência observada na região mais industrializada é de certo modo acompanhada pelas demais e apresenta um peso relativo maior no tocante à dinâmica de renda nacional, embora quanto à mobilidade dos estratos de renda o Nordeste e Norte apresentem comportamento diferenciado.

Do ponto de vista teórico um aumento da polarização pode estar relacionada com um choque tecnológico que repercute através de uma maior demanda por trabalho qualificado. $O$ aumento do prêmio por qualificação induziria a um decréscimo do ambiente local, ou seja, do efeito familiar, aumentando a mobilidade educacional. 
Figura 10 - Multiplicadores de Schrödinger - Brasil e Regiões.

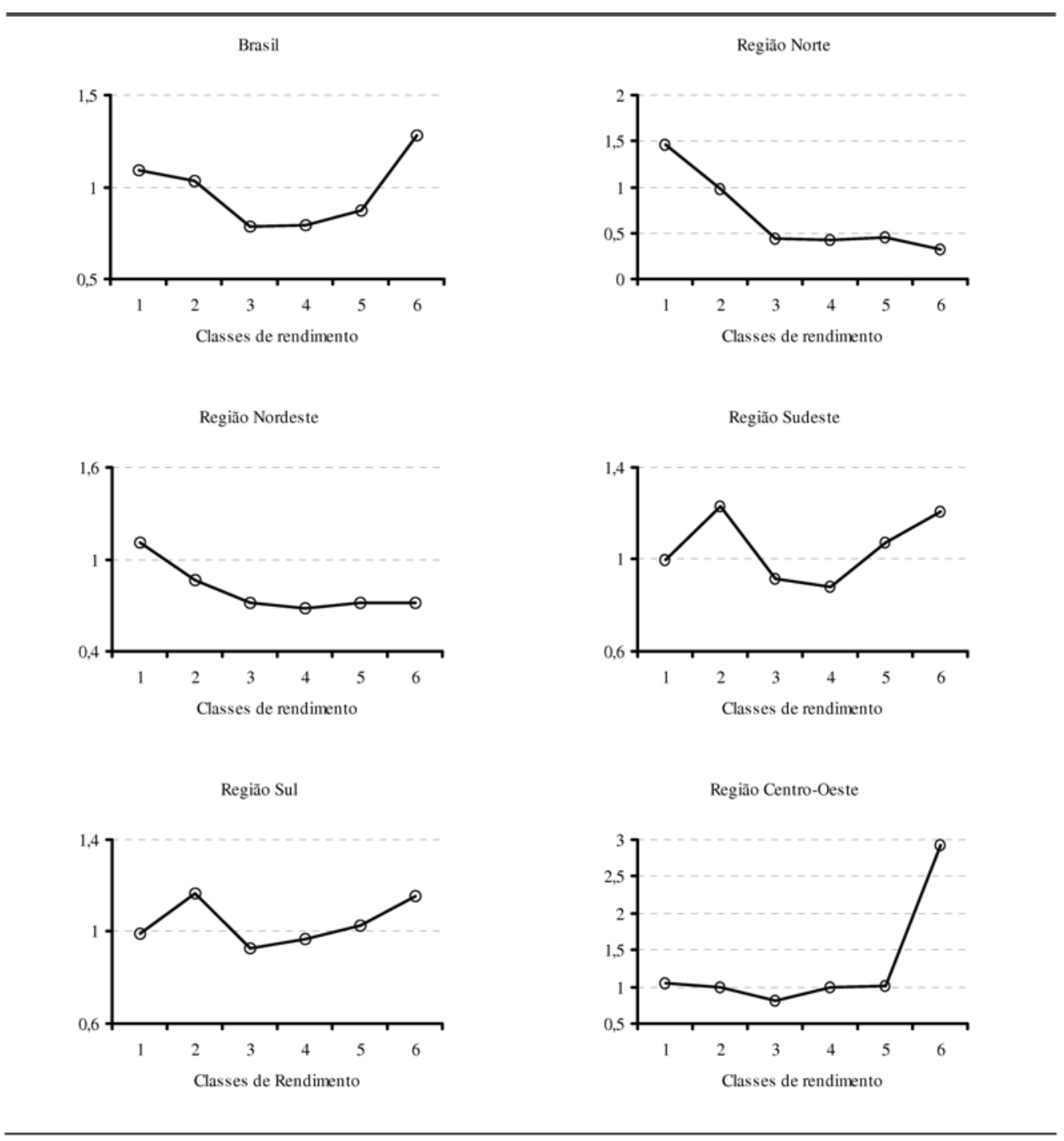

Fonte: Dados da pesquisa. 


\subsection{Dinâmica Educacional}

A dimensão da dispersão salarial entre os trabalhadores normalmente está associada a características tais como nível educacional, esforço, experiência, além de habilidades observáveis e não-observáveis. No Brasil a educação é vista como uma das principais fontes de desigualdade. Barros et alii (2000), por exemplo, ressaltam que a distribuição da educação e seus retornos respondem por quase metade da desigualdade salarial no Brasil ${ }^{17}$. Sendo assim, o caminho natural de investigação será, portanto, o de analisar a dinâmica educacional brasileira.

A Tabela 2 apresenta os resultados de um pseudo painel com vistas a explicar as relações entre anos de escolaridade, fatores regionais e o nível de rendimento salarial no Brasil e regiões. As variáveis elencadas foram anos de estudo e sexo. Além destas foi inserida uma dummie regional educacional. ${ }^{18}$

Todas as variáveis apresentaram significância estatística. A variável explicativa dicotômica sugere que homens apresentam níveis salariais superiores. A região com melhor relação anos de estudo e remuneração é o Sul, pois apresenta o maior coeficiente entre as dummies regionais, onde o Sudeste é a região base. O Nordeste é a região que apresenta a pior relação, sendo a única com dummie educacional negativa entre as demais. Tais resultados reforçam a idéia de que a educação interfere positivamente na distribuição salarial e que o peso desta variável é diferenciado entre as regiões brasileiras.

Tabela 2 - Pseudo Painel Período de 1987 a 2003

\begin{tabular}{ccrccr}
\hline Brasil & Coeficientes & $P>|z|$ & Norte & Coeficientes & $P>|z|$ \\
\hline Anos de Estudo & $0,154(0,000)$ & 0,000 & Anos de Estudo & $0,156(0,000)$ & 0,000 \\
Sexo & $0,098(0,001)$ & 0,000 & Dummie Regional & $0,008(0,000)$ & 0,000 \\
Constante & $4,651(0,024)$ & 0,000 & & & \\
\hline Nordeste & Coeficientes & $P>|z|$ & Centro-Oeste & Coeficientes & $P>|z|$ \\
\hline Anos de Estudo & $0,156(0,000)$ & 0,000 & Anos de Estudo & $0,156(0,000)$ & 0,000 \\
Dummie Regional & $-0,026(0,000)$ & 0,000 & Dummie Regional & $0,007(0,000)$ & 0,000 \\
\hline Sul & Coeficientes & $P>|z|$ & Sudeste & Coeficientes & $P>|z|$ \\
\hline Anos de Estudo & $0,156(0,000)$ & 0,000 & Anos de Estudo & $0,156(0,000)$ & 0,000 \\
Dummie Regional & $0,010(0,000)$ & 0 & Dummie Regional & - & - \\
\hline
\end{tabular}

Fonte: Dados da pesquisa. O erro padrão entre parênteses.

Observada esta relação positiva, passa-se a considerar aspectos relativos à dinâmica da educação no Brasil. Para tanto, foi estabelecido um índice de experiência dado por:

\section{Experiência $=$ Idade - Anos de Estudo - Seis Anos}

Intuitivamente, espera-se que para valores altos deste índice de experiência o indivíduo pare de acumular capital humano. Valores inferiores ou iguais a quatro foram descartados da amostra. Tal estratégia foi utilizada, por exemplo, por Checchi et alii (1999) e Birchenall (2001). Esta restrição permite o cálculo de uma matriz de transição de probabilidade para cada ano, a partir de informações relativas ao chefe da família e seus filhos na PNAD.

\footnotetext{
${ }^{17} \mathrm{O}$ número especial da Revista Brasileira de Economia v. 58, n. 2, 2004, configura uma boa referência sobre os diferenciais de salários no Brasil. Para uma análise específica do retorno da escolaridade ver Sachsida et alii (2004). Nesse estudo, pode encontrar uma discussão dos métodos de inferência e seus vieses.

${ }^{18}$ Alguns pontos devem ser esclarecidos: a) optou-se por um pseudo painel por não se dispor de informações relativas a cada indivíduo ano a ano, como já ressaltado na análise de mobilidade de renda. Logo, utilizou-se a idade dos indivíduos como "filtro"; b) a variável dependente é logaritmo da renda real; c) a dummie "sexo"foi adicionada como forma de minimizar o erro da estimação e; d) a dummie regional capta mudanças na inclinação.
} 
Tabela 3 - Mobilidade Educacional entre Gerações - Brasil - 1987

\begin{tabular}{llccccc}
\hline & & \multicolumn{5}{c}{ Nível Educacional dos Filhos (em anos) } \\
& & Primário & $1^{\circ}$ Grau & $2^{\circ}$ Grau & Superior & Total \\
& Primário (0-4) & $(0-4)$ & $(5-8)$ & $(9-12)$ & (+ de 12) & \\
\hline \multirow{3}{*}{ Nível Educacional } & $1^{\circ}$ Grau (5-8) & 0,6 & 0,25 & 0,12 & 0,03 & 1 \\
dos Pais (em anos) & $2^{\circ}$ Grau (9-12) & 0,17 & 0,32 & 0,3 & 0,16 & 1 \\
& Superior (+ de 12) & 0,11 & 0,09 & 0,33 & 0,35 & 1 \\
& & & & & & \\
\end{tabular}

Fonte: Cálculo dos autores.

A matriz de transição para 1987 é mostrada na Tabela 3. Sua diagonal principal permite observar a persistência do efeito familiar relativo à mobilidade educacional. Por exemplo, em 1987 60\% dos filhos cujos pais possuíam apenas o nível primário permaneceram nesta mesma faixa. Este resultado sugere um forte efeito dos pais na menor faixa educacional. Em 2003, tem-se uma redução do efeito familiar no menor faixa educacional e um aumento na faixa superior (ver Tabela 4).

Tabela 4 - Mobilidade Educacional entre Gerações - Brasil - 2003

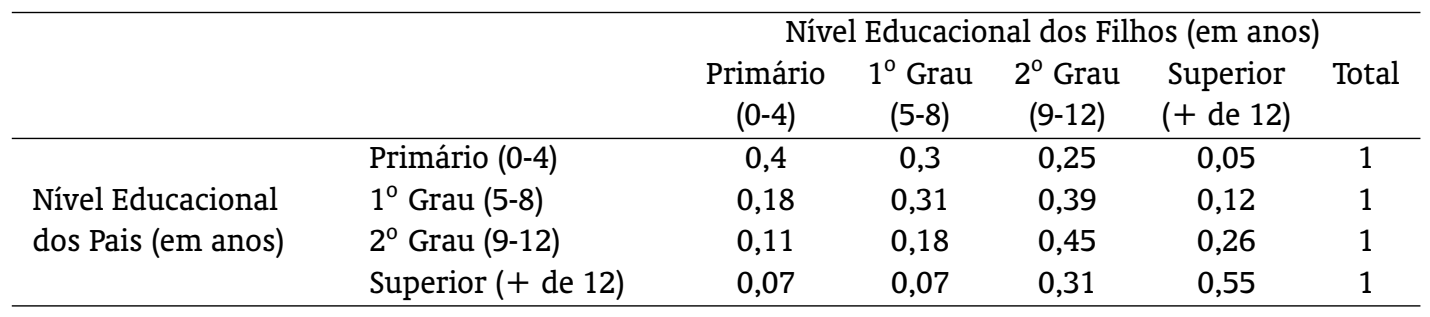

Fonte: Cálculo dos autores.

A dinâmica da mobilidade educacional será capturada a partir do cálculo dos índices de persistência das matrizes de transição $(\varpi)$. Este índice indicará o grau de mobilidade dentro dos diversos estratos de educação. Caso $\varpi=0$, a matriz de transição $P$ corresponderá a uma matriz identidade e a mobilidade dentro dos estratos será igual à zero, ou seja, o nível educacional dos pais determinará o nível educacional dos filhos. No outro limite, se $\varpi=1$ tem-se uma perfeita mobilidade e o efeito dos pais não prevalecerá. Os diversos índices considerados são definidos no quadro $11{ }^{19}$

Onde, $n$ corresponde à ordem da matriz e; $\lambda_{j}$ a seus respectivos autovalores. Todos os indicadores apresentaram comportamentos similares. O Gráfico 12 apresenta a evolução do $\omega_{L}$. Observa-se um aumento no grau mobilidade educacional no Brasil como um todo. No entanto, a partir dos anos 90 essa trajetória torna-se relativamente estável.

As regiões com maiores e menores mobilidades de renda são a Norte e Nordeste respectivamente. As trajetórias podem ser divididas em dois períodos caracterizados, respectivamente, pelo crescimento e estabilização do índice de mobilidade educacional. No primeiro período (1987-1995), a região Sudeste se destaca por apresentar uma trajetória crescente no seu indicador, estabilizando-se no período posterior. O Nordeste apresenta crescimento até 1992, permanecendo estável até 2003. No entanto, apesar do

\footnotetext{
${ }^{19}$ Estes índices podem ser interpretados como a diferença entre a matriz observada e a matriz limite do processo markoviano.
} 
Figura 11 - Índices de Mobilidade

\begin{tabular}{cccc}
\hline$\omega_{R}$ & $\omega_{A}$ & $\omega_{L}$ & $\omega_{D}$ \\
\hline$\frac{n-\sum_{j} \lambda_{j}}{n-1}$ & $\frac{n-\sum_{j}\left|\lambda_{j}\right|}{n-1}$ & $1-\left|\lambda_{2}\right|$ & $1-\left|\prod_{j} \lambda_{j}\right|^{n-1}$ \\
\hline
\end{tabular}

Fonte: Shorrocks (1978) e Geweke et alii (1986).

Nordeste apresentar a menor mobilidade educacional sua distância relativa foi reduzida em relação às demais.

Estes resultados sugerem uma redução do ambiente local, ou seja, do efeito familiar tanto para o Brasil quanto para suas regiões. Contudo, a análise do índice de mobilidade não detalha a dinâmica ocorrida entre os estratos educacionais e suas possíveis especificidades regionais.

Figura 12 - Mobilidade Educacional entre as Gerações - Brasil e Regiões

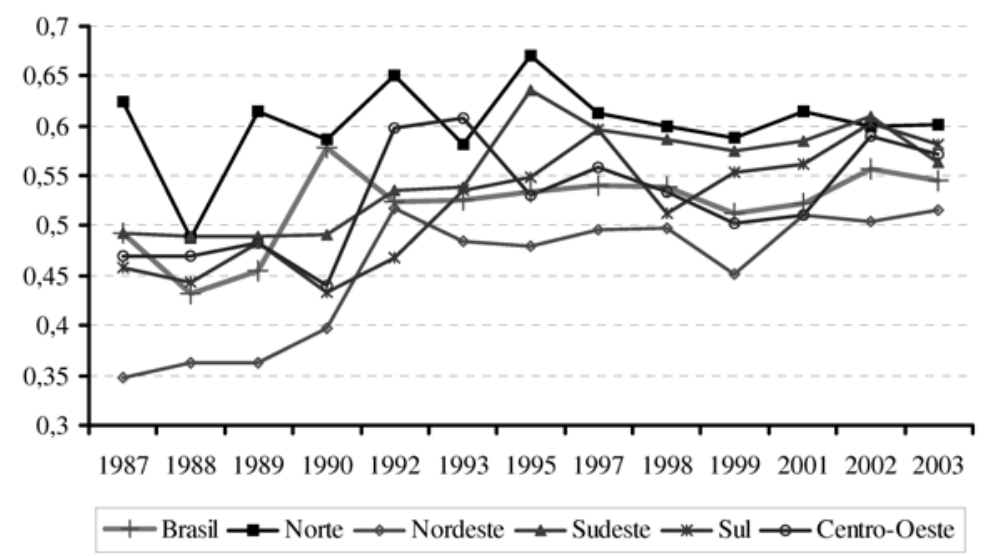

Dados da Pesquisa. Índice $\omega_{L}$

A partir da observação das matrizes de transição brasileiras (Tabelas 3 e 4), se verificou uma redução do efeito familiar nos estratos inferiores (0-4 e 5-8 anos de estudo), acompanhadas por um aumento deste efeito nos níveis educacionais mais altos (9-12 e mais de 12 anos de estudo). Entretanto, algumas regiões apresentam um comportamento diferenciado.

Nas Tabelas 5 e 6 encontram-se os resultados relativos de dois extremos no tocante a análise de mobilidade entre estratos de renda. Na região Nordeste, em 1987, 72\% dos filhos que tinham pais no nível primário permanecerem neste mesmo patamar. Este valor se reduz expressivamente para 51\% em 2003, sugerindo uma queda do efeito familiar neste estrato educacional. Vale ressaltar que o Nordeste é a região que possui a maior probabilidade nesse estrato educacional dentre as demais regiões. Outro aspecto importante a ser destacado quanto ao Nordeste é o decréscimo expressivo na probabilidade do estrato educacional mais alto, sendo, mais uma vez, a única região que apresentou tal comportamento.

Para a região Sudeste os indicadores sugerem um efeito familiar mais forte no estrato educacional 
Tabela 5 - Mobilidade Educacional entre Gerações - Região Nordeste - 1987

\begin{tabular}{llccccc}
\hline & & \multicolumn{5}{c}{ Nível Educacional dos Filhos (em anos) } \\
& & Primário & $1^{\circ}$ Grau & $2^{\circ}$ Grau & Superior & Total \\
& Primário (0-4) & $(0-4)$ & $(5-8)$ & $(9-12)$ & (+ de 12) & \\
\hline \multirow{3}{*}{ Nível Educacional } & $1^{\circ}$ Grau (5-8) & 0,72 & 0,17 & 0,09 & 0,02 & 1 \\
dos Pais (em anos) & $2^{\circ}$ Grau (9-12) & 0,17 & 0,32 & 0,3 & 0,1 & 1 \\
& Superior (+ de 12) & 0,06 & 0,12 & 0,33 & 0,3 & 1 \\
& & & & 0,22 & 0,6 & 1 \\
\hline
\end{tabular}

Fonte: Cálculo dos autores.

Tabela 6 - Mobilidade Educacional entre Gerações - Região Nordeste - 2003

\begin{tabular}{llccccc}
\hline & & \multicolumn{5}{c}{ Nível Educacional dos Filhos (em anos) } \\
& & Primário & $1^{\circ}$ Grau & $2^{\circ}$ Grau & Superior & Total \\
& Primário (0-4) & $(0-4)$ & $(5-8)$ & $(9-12)$ & (+ de 12) & \\
\hline \multirow{3}{*}{ Nível Educacional } & $1^{\circ}$ Grau (5-8) & 0,52 & 0,26 & 0,2 & 0,02 & 1 \\
dos Pais (em anos) & $2^{\circ}$ Grau (9-12) & 0,13 & 0,31 & 0,37 & 0,08 & 1 \\
& Superior (+ de 12) & 0,1 & 0,19 & 0,46 & 0,22 & 1 \\
& & & & 0,3 & 0,5 & 1 \\
\hline
\end{tabular}

Fonte: Cálculo dos autores.

mais elevado, além de uma redução do efeito nos estratos mais baixos, principalmente, na faixa de ensino primário (ver tabelas 7 e 8). De 1987 a 2003 houve uma redução da probabilidade do estrato mais baixo em mais de $20 \%$, enquanto que a probabilidade do estrato educacional mais alto se manteve inalterada.

Tabela 7 - Mobilidade Educacional entre Gerações - Região Sudeste - 1987

\begin{tabular}{llccccc}
\hline & & \multicolumn{5}{c}{ Nível Educacional dos Filhos (em anos) } \\
& & Primário & $1^{\circ}$ Grau & $2^{\circ}$ Grau & Superior & Total \\
& & $(0-4)$ & $(5-8)$ & $(9-12)$ & (+ de 12) & \\
\hline \multirow{3}{*}{ Nível Educacional } & Primário (0-4) & 0,51 & 0,28 & 0,15 & 0,06 & 1 \\
dos Pais (em anos) & $1^{\circ}$ Grau (5-8) & 0,17 & 0,29 & 0,31 & 0,23 & 1 \\
& $2^{\circ}$ Grau (9-12) & 0,12 & 0,13 & 0,36 & 0,39 & 1 \\
& Superior (+ de 12) & 0,07 & 0,05 & 0,27 & 0,61 & 1 \\
\hline
\end{tabular}

Fonte: Cálculo dos autores.

Tais resultados são consistentes do ponto de vista teórico dado que sugerem um aumento na força dos fatores externos quando a decisão de investir em educação, refletidos numa maior mobilidade educacional. Como já realçado na exposição do modelo teórico, um choque tecnológico implica na diminuição do efeito familiar, ou seja, em uma queda na probabilidade de se manter no mesmo estrato educacional dos pais, e uma prevalência do efeito global, caracterizada pelo aumento relativo da remu- 
neração dos trabalhadores qualificados.

Tabela 8 - Mobilidade Educacional entre Gerações - Sudeste - 2003

\begin{tabular}{llccccc}
\hline & & \multicolumn{5}{c}{ Nível Educacional dos Filhos (em anos) } \\
& & Primário & $1^{\circ}$ Grau & $2^{\circ}$ Grau & Superior & Total \\
& Primário (0-4) & $(0-4)$ & $(5-8)$ & $(9-12)$ & (+ de 12) & \\
\hline \multirow{3}{*}{ Nível Educacional } & $1^{\circ}$ Grau (5-8) & 0,3 & 0,31 & 0,32 & 0,07 & 1 \\
dos Pais (em anos) & $2^{\circ}$ Grau (9-12) & 0,14 & 0,27 & 0,43 & 0,16 & 1 \\
& Superior (+ de 12) & 0,05 & 0,13 & 0,46 & 0,31 & 1 \\
& & & & & & \\
\hline
\end{tabular}

Fonte: Cálculo dos autores.

No entanto, no Nordeste, ao contrário das demais regiões, o efeito familiar da faixa educacional mais baixa, continua sendo mais forte, apesar da redução ter sido significativa. Apesar de regionalmente diferenciados os resultados concernentes ao índice de mobilidade educacional reforçam os pontos sugeridos no modelo teórico quanto à mobilidade de renda e polarização. Vale ressaltar, que diversos fatores relevantes de natureza institucional não foram considerados ao longo da análise.

\section{CONSIDERAÇÕES FINAIS}

Este estudo buscou investigar a natureza das mudanças na distribuição de renda do Brasil e regiões no período de 1987 a 2003 e, adicionalmente, identificar os fatores motivadores de tais transformações ressaltando os aspectos inerentes às mobilidades de renda e educacional. A distribuição de renda do Brasil apresentou transformações expressivas do ponto de vista estático neste período. No entanto, os indicadores de desigualdade de renda não captaram tais mudanças.

Tais transformações puderam ser detectadas pelas medidas de polarização. Tanto o Brasil como suas regiões apresentaram um forte aumento deste indicador de um modo geral. No entanto, podem ser destacados três períodos no tocante à sua trajetória: o primeiro refere-se ao intervalo 1987-1995, onde se observa um crescimento paulatino da polarização; o segundo que se estende de 1995-1999, é marcado por um decréscimo deste índice e; o trecho final de 1999-2003 marca uma retomada no seu crescimento.

Em linhas gerais podem-se listar as seguintes transformações: a) houve uma diminuição do índice de gini para todas as regiões tornando as distribuições mais eqüitativas; b) aumentou o índice de polarização para todas as regiões; c) a polarização no Nordeste beneficiou o menor estrato de renda; d) na região Sudeste há um aumento da polarização nos estratos superiores de renda; e) do ponto de vista da mobilidade de renda, observou-se um esvaziamento das classes intermediárias.

No tocante à mobilidade educacional constatou-se um forte aumento no período analisado. Tais resultados sugerem um decréscimo do efeito familiar nas faixas educacionais mais baixas apresentando, no entanto, distinções regionais. Na região Nordeste, por exemplo, apesar da redução do efeito familiar da faixa educacional mais baixa há também uma redução significativa da faixa mais alta, ao contrário das demais regiões. Este comportamento do Nordeste sugere que a região pode estar presa em uma armadilha de pobreza.

Os resultados em princípio parecem reforçar as conclusões do modelo teórico, onde um choque tecnológico tende a criar um cenário de maior polarização de renda decorrente do aumento do prêmio por qualificação. Quanto à mobilidade educacional, o modelo teórico sinaliza um aumento do efeito global, conseqüente do choque tecnológico, que reduz o efeito familiar, sobretudo nas faixas mais baixas 
o que repercute em um aumento da mobilidade educacional, fenômeno este em consonância com os resultados apresentados por este trabalho.

Nota Adicional Todas as estimações foram realizadas nos softwares Statistics Data Analysis (STATA 8.0) e GAUSS Mathematical and Statistical System 6.0.

\section{Referências Bibliográficas}

Aebi, R. \& Nagasawa, M. (1992). Large derivations and propagation of chaos for schrödinger processes. Probability Theory and Related Fields, 94(1):53-68.

Aebi, R., Neusser, K., \& Steiner, P. (2001). Improving models of income dynamics using cross-section information. Technical report, University of Berne.

Atkinson, A. (1970). On the measurement of inequality. Journal of Economic Theory, 2(1):244-263.

Barros, R. P., Henriques, R., \& Mendonça, R. (2000). Education and equitable economic development. Economia, 1(1):111-144.

Birchenall, J. A. (2001). Income distribution, human capital and economic growth in colombia. Journal of Development Economics, 66(1):271-287. available at http://ideas.repec.org/a/eee/deveco/ v66y2001i1p271-287.html.

Blackburn, M. L. \& Bloom, D. E. (1985). What is happening to the middle class? American Demographics, 7(1):18-25.

Burkhauser, R. V., Cutts, A. C., Daly, M. C., \& Jenkins, S. P. (1999). Testing the significance of income distribution changes over the 1980s business cycle: a cross-national comparison. Journal of Applied Econometrics, 14(3):253-272.

Burtless, G. (1997). The progress and distribution of u.s. living standards - 1959-1990. The North American Journal of Economics and Finance, 8(2):111-133.

Carneiro, F. G. \& Arbache, J. S. (2003). The impacts on the brazilian labor market: a cge model approach. World Development, 31(9):1581-1595.

Checchi, D., Ichino, A., \& Rustichini, A. (1999). More equal but less mobile?: Education financing and intergenerational mobility in italy and in the us. Journal of Public Economics, 74(3):351-393. available at http://ideas.repec.org/a/eee/pubeco/v74y1999i3p351-393.html.

Diniz, C. (1995). A dinâmica regional recente da economia brasileira e suas perspectivas. Texto para discussão 385, Rio de Janeiro: IPEA.

Duclos, J.Y., Esteban, J., \& Ray, D. (2004). Polarization: concepts, measurement, estimation. Econometrica, 72(6):1737-1772.

Esteban, J. \& Ray, D. (1994). On the measurement of polarization. Econometrica, 62(4):819-851.

Galor, O. \& Tsiddon, D. (1997). Technological progress, mobility and economic growth. The American Economic Review, 87(3):363-382.

Galor, O. \& Zeira, J. (1993). Income distribution and macroeconomics. Review of Economics Studies, 60(1):35-52. 
Geweke, J., Marshall, R., \& Zarkin, G. (1986). Mobility indices in continuous time markov chains. Econometrica, 54(6):1407-1423.

Gonzaga, G., Menezes Filho, N., \& Terra, M. C. (2006). Trade liberalization and the evolution of skill earnings differentials in brazil. Journal of International Economics, 68(2):345-367.

Green, F., Dickerson, A., \& Arbache, J. S. (2001). A picture of wage inequality and the allocation of labor through a period of trade liberalization: the case of brazil. World Development, 29:1923-1939.

Griliches, Z. \& Mason, W. (1972). Education income, and ability. Journal of Political Economy, 80(3):74103.

Jenkins, S. P. (1995). Did the middle class shrink during the 1980s? uk evidence from kernel density estimates. Economic Letters, 49(4):407-413.

Juhn, C., Murphy, K., \& Pierce, B. (1993). Wage inequality and the rise in returns to skill. Journal of Political Economy, 101(3):410-442.

Lenz, B. \& Laband, D. (1989). Why so many children of doctors become doctors. Journal of Human Resources, 24(3):396-413.

Maia, K. (2001). Progresso tecnológico, qualificação de mão-de-obra e desemprego. Tese de Doutorado, UNB.

Menezes Filho, N. A. \& Rodrigues Junior, M. (2003). Tecnologia e demanda por qualificação na indústria brasileira. Revista Brasileira de Economia, 57(3):569-603.

Milanovic, B. (2000). A new polarization measure and some applications. Development Research Group, Word Bank.

Pollard, D. (1984). Convergence of stochastic processes. New York: Springer-Verlag.

Quah, D. (1997). Empirics for growth and distribution: stratification, polarization and convergence clubs. Journal of Economic Growth, 2(1):27-59.

Saboia, J. (2001). Descentralização industrial no brasil na década de noventa: um processo dinâmico e diferenciado regionalmente. Nova Economia, 11(2):85-122.

Sachsida, A., Loureiro, P., \& Mendonça, M. (2004). Um estudo sobre o retorno em escolaridade no brasil. Revista Brasileira de Economia, 58(2):249-265.

Shorrocks, A. (1978). The measurement of mobility. Econometrica, 46(5):1013-1024.

Silverman, B. (1986). Density estimation for statistics and data analysis. London: Chapman \& Hall.

Soares, S., Servo, L. S., \& Arbache, J. S. (2001). O que (não) sabemos sobre a relação entre abertura comercial e mercado de trabalho no brasil. Texto para discussã 843, Rio de Janeiro: IPEA.

Wolfson, M. C. (1994). When inequalities diverge. The American Economic Review, 84(2):353-358.

\section{A. ÍNDICE DE GINI, POLARIZAÇÃO E MOBILIDADE EDUCACIONAL}


Tabela 9 - Índice de Gini - Brasil e Regiões

\begin{tabular}{|ccccccc|}
\hline & 1987 & 1989 & 1990 & 1992 & 1993 & 1995 \\
\hline Brasil & 0,594 & 0,634 & 0,611 & 0,565 & 0,604 & 0,587 \\
Norte & 0,554 & 0,615 & 0,599 & 0,541 & 0,591 & 0,578 \\
Nordeste & 0,624 & 0,659 & 0,632 & 0,591 & 0,642 & 0,601 \\
Sudeste & 0,574 & 0,613 & 0,592 & 0,537 & 0,575 & 0,565 \\
Sul & 0,564 & 0,587 & 0,57 & 0,539 & 0,568 & 0,561 \\
Centro-Oeste & 0,593 & 0,623 & 0,613 & 0,577 & 0,607 & 0,584 \\
\hline & 1997 & 1998 & 1999 & 2001 & 2002 & 2003 \\
\hline Brasil & 0,582 & 0,583 & 0,492 & 0,568 & 0,566 & 0,554 \\
Norte & 0,574 & 0,579 & 0,556 & 0,544 & 0,552 & 0,524 \\
Nordeste & 0,6 & 0,597 & 0,594 & 0,586 & 0,581 & 0,567 \\
Sudeste & 0,554 & 0,554 & 0,541 & 0,547 & 0,538 & 0,534 \\
Sul & 0,546 & 0,552 & 0,542 & 0,53 & 0,526 & 0,527 \\
Centro-Oeste & 0,596 & 0,596 & 0,582 & 0,579 & 0,584 & 0,558 \\
\hline
\end{tabular}

Fonte: Cálculo dos autores.

Tabela 10 - Índice de Polarização - Brasil e Regiões

\begin{tabular}{|ccccccc|}
\hline & 1987 & 1989 & 1990 & 1992 & 1993 & 1995 \\
\hline Brasil & 0,302 & 0,366 & 0,338 & 0,363 & 0,382 & 0,564 \\
Norte & 0,165 & 0,174 & 0,174 & 0,178 & 0,203 & 0,216 \\
Nordeste & 0,202 & 0,233 & 0,249 & 0,231 & 0,249 & 0,339 \\
Sudeste & 0,22 & 0,283 & 0,254 & 0,293 & 0,314 & 0,371 \\
Sul & 0,18 & 0,185 & 0,186 & 0,214 & 0,228 & 0,251 \\
Centro-Oeste & 0,173 & 0,182 & 0,194 & 0,209 & 0,24 & 0,266 \\
\hline & 1997 & 1998 & 1999 & 2001 & 2002 & 2003 \\
\hline Brasil & 0,452 & 0,359 & 0,368 & 0,437 & 0,558 & 0,484 \\
Norte & 0,204 & 0,182 & 0,18 & 0,215 & 0,279 & 0,241 \\
Nordeste & 0,301 & 0,254 & 0,255 & 0,359 & 0,372 & 0,359 \\
Sudeste & 0,297 & 0,248 & 0,258 & 0,265 & 0,329 & 0,295 \\
Sul & 0,215 & 0,189 & 0,203 & 0,209 & 0,241 & 0,226 \\
Centro-Oeste & 0,221 & 0,202 & 0,196 & 0,209 & 0,256 & 0,237 \\
\hline
\end{tabular}

Fonte: Cálculo dos autores. 
Tabela 11 - Mobilidade Educacional entre as Gerações - Brasil e Regiões

\begin{tabular}{|ccccccc|}
\hline & 1987 & 1989 & 1990 & 1992 & 1993 & 1995 \\
\hline Brasil & 0,493 & 0,455 & 0,579 & 0,524 & 0,525 & 0,533 \\
Norte & 0,625 & 0,615 & 0,586 & 0,651 & 0,581 & 0,67 \\
Nordeste & 0,348 & 0,362 & 0,397 & 0,518 & 0,485 & 0,48 \\
Sudeste & 0,493 & 0,489 & 0,491 & 0,535 & 0,539 & 0,635 \\
Sul & 0,458 & 0,483 & 0,434 & 0,468 & 0,535 & 0,548 \\
Centro-Oeste & 0,47 & 0,482 & 0,44 & 0,598 & 0,608 & 0,531 \\
\hline & 1997 & 1998 & 1999 & 2001 & 2002 & 2003 \\
\hline Brasil & 0,541 & 0,538 & 0,513 & 0,522 & 0,557 & 0,545 \\
Norte & 0,613 & 0,599 & 0,588 & 0,614 & 0,6 & 0,602 \\
Nordeste & 0,496 & 0,498 & 0,452 & 0,511 & 0,504 & 0,516 \\
Sudeste & 0,597 & 0,586 & 0,575 & 0,584 & 0,61 & 0,564 \\
Sul & 0,597 & 0,513 & 0,553 & 0,562 & 0,603 & 0,581 \\
Centro-Oeste & 0,559 & 0,533 & 0,503 & 0,511 & 0,59 & 0,571 \\
\hline
\end{tabular}

Fonte: Cálculo dos autores. 